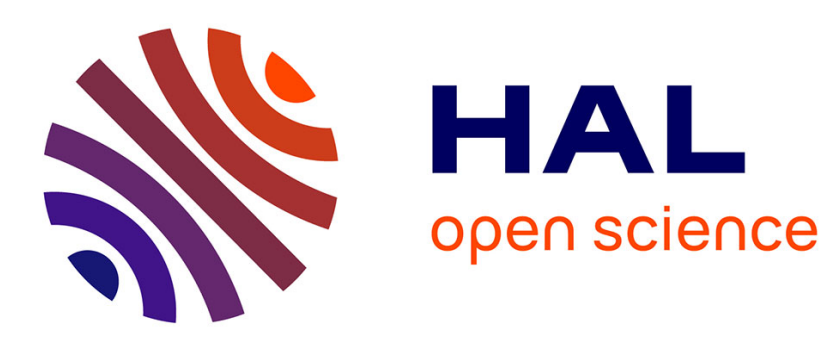

\title{
Organising for future crises: the case of integrated risk management in French cities
}

\author{
Mathilde Gralepois
}

\section{To cite this version:}

Mathilde Gralepois. Organising for future crises: the case of integrated risk management in French cities. International Journal of Emergency Management, 2006, 3 (1), pp.91-97. halshs-00406492

\section{HAL Id: halshs-00406492 \\ https://shs.hal.science/halshs-00406492}

Submitted on 22 Jul 2009

HAL is a multi-disciplinary open access archive for the deposit and dissemination of scientific research documents, whether they are published or not. The documents may come from teaching and research institutions in France or abroad, or from public or private research centers.
L'archive ouverte pluridisciplinaire HAL, est destinée au dépôt et à la diffusion de documents scientifiques de niveau recherche, publiés ou non, émanant des établissements d'enseignement et de recherche français ou étrangers, des laboratoires publics ou privés. 


\title{
Organising for future crises: the case of integrated risk management in French cities
}

\author{
Arjen Boin and Mathilde Gralepois* \\ Department of Public Administration \\ Leiden University \\ P.O. Box 9555 \\ 2300 RB Leiden, The Netherlands \\ E-mail: BOIN@fsw.leidenuniv.nl \\ E-mail: Mathilde.Gralepois@mail.enpc.fr \\ *Corresponding author
}

\begin{abstract}
Public leaders face a set of crisis management tasks that are not easy to fulfill. It becomes especially challenging in large cities, which bring together potentially dangerous technologies and large masses of people. Coping with an emerging crisis in this context is a daunting task, if only because of infrastructural bottle necks and a lack of available means. What answers do city governments produce? For a particular interesting development, we turn to a group of French large cities which have seen the emergence of a new form of risk management: the integrated risk institute. In this article, we briefly survey emerging developments and challenges in these cities and formulate questions for a research agenda on urban crisis management.
\end{abstract}

Keywords: urban crisis management; French cities; future crises.

Reference to this paper should be made as follows: Boin, A. and Gralepois, M. ( $\mathrm{xxxx})$ 'Organising for future crises: the case of integrated risk management in French cities', Int. J. Emergency Management, Vol. X, No. Y, pp.000-000.

Biographical notes: Arjen Boin is Associate Professor at Leiden University, Department of Public Administration and Director of the Leiden University Crisis Research Center. His latest book is The Politics of Crisis Management (Cambridge University Press, coauthored with Paul 't Hart, Eric Stern and Bengt Sundelius). Boin is cofounder of the European Crisis Management Academy (ECMA).

Mathilde Gralepois has a $\mathrm{PhD}$ and is researcher in the Public Administration and Territorial Dynamics Research Center (LATTS) at the French Public Engineering Institute (ENPC) in Marne-la-Vallée. She is especially working on French decentralisation of risks administration.

\section{Introduction: emerging challenges in the crisis arena}

In contemporary Western societies, public leaders face a set of challenges that together constitute the task of crisis management (Boin et al., 2005). They must prevent known risks from materialising or at least recognise developing crises in time; once a crisis becomes manifest, leaders must make critical decisions and facilitate a coordinated 
response to minimise the consequences of crisis; they must explain to citizens, victims, clients and stakeholders what went wrong and what they could do to manage the crisis; they must deal with formal accountability fora and consider what lessons can be learned to prevent the crisis from happening again.

This set of interrelated tasks is not easy to fulfil. It becomes especially challenging in urban cities (Rosenthal et al., 1994). Large cities bring together potentially dangerous technologies and large masses of people; crises should therefore be considered 'normal' occurrences (Perrow, 1999). Coping with an emerging crisis is a daunting task, if only because of infrastructural bottlenecks and a lack of available means. Learning the right lessons is hindered by the complexity of the urban environment: city administrators simply do not fully understand the multicultural city and its citizens.

A number of long-term trends further compound the difficulties experienced by city leaders. Three appear especially relevant for contemporary leaders across the governmental spectrum:

1 The growing complexity of social, corporate, industrial, financial, infrastructural and administrative systems - and the tight coupling between these systems - produce unforeseen disturbances that can assume previously inconceivable shapes and proportions (Turner and Pidgeon, 1997; Perrow, 1999). As the cause of the disturbance is unclear, it is easy to make wrong decisions that fuel rather than dampen the crisis at hand.

2 The societal and political climate in which leaders must try to deal with new and old crises has made it harder for leaders to deal with system disturbances. Politicians and citizens alike display low tolerance for even minor disturbances; the media are all too willing to report incidents into crises. Together, these actors force leaders to take rapid and often ill-considered decisions that fuel rather than dampen the crisis at hand.

3 The administrative structures of crisis management have become increasingly opaque. After the 9/11 and 3/11 events in the USA and Europe, governmental responses in many countries have been driven by the so-called 'centralisation reflex'. This drive to redesign administrative structures betrays a fundamental but ill-informed belief in symbolic leadership measures. System disturbances, however, typically require flexibility, redundancy and resilience (for which these 'modern' structures have little tolerance).

This combination of difficult tasks and emerging challenges seems to render obsolete traditional ways of organising for crises (Boin and Lagadec, 2000). If this is the case, we ask, what answers do urban cities produce? For a particularly interesting development we turn to a group of large French cities, which have been wrestling with precisely this question.

\section{Local risk management in large French cities ${ }^{1}$}

In France, a relatively small group of cities has seen the emergence of a new form of risk management: the integrated risk institute. The private sector had seen the development of integrated risk management. In addition, the national policy 'Politique de la Ville' 
emerged in the early 1990s, which addressed inner-city problems, such as ethical integration, urban violence, and housing for the poor in an integrated way.

A select set of local institutions decided to integrate local risk management issues. This integrated risk perspective, which is considered an administrative innovation, exists besides the traditional, sectorised perspective that continues to dominate in other cities. ${ }^{2}$

This trend towards integrated risk management is set against the backdrop of a centralised nation in which new local policies are always considered a step toward decentralisation. The French state still sends national civil servants to govern local administrative institutions (the 'préfets' in the 'région' and the 'départements') where they work both for the national and the local administrative levels. This paradoxical situation creates a difficult environment for risk and crisis management. Local risk management, after all, requires a clear distribution of responsibilities and a capacity for intelligent regulation.

\subsection{The emerging identity of local risk management departments}

In the cities and regions under study, the local risk management departments displayed an interpretation of risk and a fitting organisational culture, which, together, can be said to constitute a distinct organisational identity. This development appears to be the result of deliberate political choice rather than just geographical or geological features. These local governments have opted to create an innovative perspective on local risk management. They have created their own answer to future crises, because national laws provide little guidance to local institutions.

The observed risk management departments are viewed as a long-term strategic tool for urban planning and economic development, as well as an urban technical service. Natural and industrial risks are not treated separately; they are integrated in a comprehensive civil defense perspective. This perspective relates a variety of risks to the emergency services of a city.

The most interesting development may be the emergence of a shared risk culture within these organisations. Tasks are increasingly defined in an interdisciplinary manner. Risk and crisis managers used to be the domain of engineers and lawyers. The qualifications of these professions no longer suffice, however. Multidisciplinary profiles and training are becoming more and more important. The management of contemporary and future crises demands a sense of curiosity, an open-minded attitude, flexibility, creativity, and, most of all, a capacity for understanding, discussion and negotiation among different actors.

The managers of the departments under discussion are highly motivated to create innovative risk management organisations. They are eager to develop their own practices, their own ways of working and organising, a professional culture that fits it all. They provide the rather abstract national policies with local 'hands and feet.'

If this trend is to be sustained, traditional bureaucrats in city administration must be convinced of its potential usefulness. At the local level, a common culture of risk must be developed. This requires a political and administrative trajectory of deliberation, evaluation, and policy-making. Risk managers typically find the relevance of such a project self-evident. But it is not necessarily the case in other parts of the city administration; national civil servants and citizens must also be convinced. 
The departments are still negotiating between traditional bureaucratic structures and the requirements of a new crisis management organisation. At the same time, this 'birth' phase of the new risk departments allows room for innovative approaches and procedures that may help to institutionalise flexibility.

\subsection{Challenges of institutionalising a collective risk culture}

This local drive for a shared risk culture runs into barriers. Interpretations differ: some local institutions have a very reactive orientation, whereas others emphasise research, prevention and forecasting. To complicate matters, city administrations still have difficulties with integrated risk approaches. Organisational charts tend to display strict functional separations and the administrative reflex to look for standardised methods that can be used in different situations remains strong.

The development of a shared risk culture is further compounded by the strained relation between administrators and politicians. Risk experts and managers face various problems of cooperation in their relation with local politicians. They lack budgetary, technical and human means, but also political and legal support. This gives risk managers a feeling of being undervalued. Risk managers also experience a lack of credibility. They hesitate between raising risk awareness and underplaying risks (in order not to frighten politicians). The lack of meaningful debate between the risk departments, local administrations, the other departments and politicians is frequently mentioned as a source of concern.

This rigid relationship does not allow for simple rules and comprehensible organisational schemes. The mayor's responsibility and means as the emergency head, whenever risk threatens his commune, are not clearly defined; the resulting relation is tense and certainly does not help the construction of a widely shared culture of risk management. Local risk management departments have difficulties in defining an effective role for the mayor that fits juridical powers, as well as administrative responsibilities. The State remains master and the guarantor of the citizens' safety on the whole territory, because of the presence of the prefect and of the different devolved services.

The balance of powers between the mayor and the prefect is yet another factor. The mayor has to answer to higher authorities when he intervenes as a representative of the State's authority. However, he only has to abide by the law when he acts as a representative of the municipality. His authority is under both political surveillance of the municipal council, and the administrative control of the State's representative prefect. The ambiguity can be summed up in the fact that the prefect has a general police authority that overlaps the mayor's municipal police powers. The prefect exerts this authority when the mayor cannot deal with the situation or when the endangered territory extends the limits of the communes.

The media complicates matters as they influence the perceived importance of certain risks both in the eyes of the general public and on the political scene; it sometimes seems as if the only risks that can be treated are the mediatised ones. Risk managers tend to agree that transparency is necessary, in order to facilitate informed debate. But it remains an open question just how much transparency is needed to have a productive debate. 


\section{An agenda for research}

We have sketched the outlines of an intriguing development: local institutions are shaping their response capacity in the face of contemporary and future crises. Their efforts are constrained by the 'normal' factors of law, culture and administrative structure.

The question is what crisis researchers can do to nurture these developments towards an integrative perspective on crisis and risk management. If we consider the research findings in the various subfields of crisis research, the following agenda for interdisciplinary research - quite a challenge in itself - on crises and crisis management emerges:

- Crisis researchers should demonstrate that urban crises do not follow simple rules of causation. Crisis researchers have traditionally formulated middle-range theories for specific types of crisis. Hence, serious work can be found, for instance, on prison riots, hurricanes, international conflicts and economic adversity. But this fragmentation of research findings makes it very hard to produce generic insights that policy makers could act upon without encountering unintended consequences of their interventions. Crisis researchers need to explore whether a common framework can be formulated (or borrowed) that will help to explain the complex causal chain that precedes urban crises. ${ }^{3}$ That may help local crisis managers to build a shared risk culture.

- An additional research challenge pertains to the politics of crisis: why do people experience some events as a threat and ignore what may appear to outside observers as rather obvious threats? Why do media and politics select from the sea of potential issues that particular issue, jointly elevating it to a crisis? Why are some events of adversity remembered as time-defining disasters, whereas others disappear in the vaults of history? If researchers can develop an understanding of the seemingly random way in which people pay attention to risks, threats and adverse events, they may help local risk managers to grasp the environment in which politicians must make critical calls. It is this understanding that may provide for a better developed relation - based on a common understanding - between local risk managers and crisis managers.

- Crisis researchers must make an urgent effort to define, identify and map best practices. The problem is the lack of a widely agreed upon normative framework, which sets out the tasks of crisis management and prescribes the guiding principles for fulfilling those tasks. In the absence of such a framework, the search for best practices amounts to little more than a description of heroic leaders and happy crisis endings. If researchers can set out such a framework, it can serve as a base for a systematic investigation into crisis management performance.

\section{Fruitful initiatives}

A concerted drive is needed to build a community of crisis researchers who are willing to work in a multi-disciplinary effort to further our theoretical knowledge about crises and crisis management. This is no easy task. It requires academic engineers who can build bridges between the various fields that would have to be connected before we can speak 
of a crisis field. At the very least, a dialogue must be initiated and sustained among disaster sociologists, students of (local) government and international relations, geographers and engineers, business students and communication (media) experts. These fields harbour developed notions of crisis (or whatever label they use for the threat of adversity) that can and should be reconciled. The key initiative would be to bring together academic leaders from these various fields and have them collaborate in joint research projects. Only through working together do we learn to understand each other.

Experienced crisis managers remain the untapped source for crucial insights with regard to what works and what does not. An interesting initiative, pioneered by Patrick Lagadec and his collaborators, is the organisation of debriefings in the wake of crises. Providing a friendly but serious setting in which practitioners can reflect upon recent events and discuss their strategies and the subsequent outcomes with colleagues, stakeholders and academics has proven beneficial to all involved. This initiative deserves replication in more countries and in many more sectors. A potential follow-up would be the involvement of these practitioners in the design of curriculum, scenarios, and simulations from which our future leaders can benefit.

One of the most persistent sources of dismay in academic circles is the consistent disregard for their research findings in policy circles. Time and again, academics see policy initiatives that have been proven ineffective in the past (the latest example being the colour code warning system in the USA). At the same time, many inventive administrators shake their head at the impractical theories forwarded by academics and wonder when these same academics will visit them to learn how they try to deal with the crises of the future. Academics should remain committed to empirical research, so that local inventions do not go unnoticed - to the greater benefit of both practice and theory.

\section{References}

Boin, R.A. and Lagadec, P. (2000) 'Preparing for the future: critical challenges in crisis management', Journal of Contingencies and Crisis Management, Vol. 8, No. 4, pp.185-191.

Boin, R.A., 't Hart, P., Stern, E. and Sundelius, B. (2005) The Politics of Crisis Management: Public Leadership Under Pressure, Cambridge: Cambridge University Press.

Buchanan, M. (2000) Ubiquity: Why Catastrophes Happen, New York: Three Rivers Press.

Perrow, C. (1999) Normal Accidents: Living with High-Risk Technologies, 2nd ed., Princeton: Princeton University Press.

Rosenthal, U., 't Hart, P., Van Duin, M.J., Boin, R.A., Kroon, M.B.R., Otten, M.H.P. and Overdijk, W.I.E. (1994) Complexity in Urban Crisis Management: Amsterdam's Response to the Bijlmer Air Disaster, London: James \& James.

Turner, B.A. and Pidgeon, N. (1997) Man-Made Disasters, 2nd ed., London: ButterworthHeinemann. 


\section{Notes}

1 This section draws from Mathilde Gralepois (2004) - The Organisation of Local Risk Management in French Public Institutions (Research master report, now the subject of her $\mathrm{PhD}$ research). The study is on risk managers in the local public institutions of four cities (Cannes, Toulouse, Marseille, Lyon) and two 'urban public communities' (Nantes Métropole and Grand Lyon).

2 Risk management is organised in more traditional departments, such as 'Civil security', 'Public Health' or 'Environment'.

3 The rapidly expanding field of complexity theory may hold the promise of delivering such a framework. For an introduction to this line of inquiry, see Buchanan (2000). 